\title{
Dependence of flexural behaviour of fibre reinforced mortar on material fracture resistance and beam size
}

\author{
R J Ward* and V C Li**
}

\begin{abstract}
The flexural load-deflection curves for mortar reinforced with various fibre types (steel and synthetic) and various fibre volume fractions are measured using three different beam sizes. Three new flexural toughness indexes that reflect the general shape of the load-deflection curve are defined and calculated. The flexural strength/tensile strength ratio $f_{1} / f_{i}$ is proposed as a parameter that reflects material brittleness - a lower value for a more brittle material. Good correlations between two of the new flexural toughness indexes and parameters that involve only $\mathrm{f}_{\mathrm{f}} \mathrm{f}_{\mathrm{t}}$ and the fibre length are found. These results indicate the possibility of getting a good idea of the flexural load-deflection curve by measuring only $\mathrm{f}_{\mathrm{f}}$ and $\mathrm{f}_{\mathrm{f}}$ in the laboratory. By realizing the dependence of structural behaviour on material fracture resistance, and also the ability of the parameters $f_{1}$ and $f_{1}$ to characterize this dependence, it is possible to develop simple formulae that directly express this dependence.
\end{abstract}

Conventional concrete design has relied almost exclusively on compressive strength as a means of specifying the concrete quality. Other concrete properties, such as tensile strength, modulus, durability, etc, have been empirically related to the compressive strength. However, the recent development and everincreasing use of both high-strength concrete (130 MPa compressive strength concrete was used in Seattle's Two Union Square Building) and fibre reinforced concrete has forced us to look more closely at concrete properties other than the compressive strength. Ordinary strength concrete fails by aggregates pulling out of the matrix, resulting in a rough fracture surface. In contrast, high. strength concrete, because of the high interfacial-bond strength between the aggregate and the mortar, fails by cracks passing straight through the aggregate, resulting in a smooth fracture plane. Concrete reinforced with low. volume fractions (up to two percent) of short fibres has a compressive strength very similar to that of the unreinforced concrete, but exhibits much greater resistance to crack formation and growth. It is obvious that compressive strength alone is not adequate for the design of the fibre concrete structures.

Material fracture resistance is an important property that can successfully distinguish between the failure modes of high-strength concrete, ordinary strength concrete, and fibre reinforced concrete. The complete tensile behaviour of concrete can be defined using the stress-strain curve and the tension-softening curve. Hillerborg' introduced the material characteristic length $l_{c h}=G_{f} E / f_{t}^{2}$ to define material tensile brittleness. $G_{F}$ is the fracture energy, $E$ is the Young's modulus, and $f_{l}$ is the tensile strength. $l_{c h}$ is a measure of the ratio of the upward slope of the stress-strain curve to the downward slope of the tension-softening curve. A material with a relatively sharp descending softening curve has a low $l_{c h}$ value and is perceived as being relatively brittle. Since high-strength concrete attains a

\footnotetext{
- Cygna Consulting Engineers, Boston, MA, USA.

"* Advanced Civil Engineering Materials Research Laboratory, Dept. Civil Engineering. University of Michigan, M148109-2125, USA. Tel: + 1 (313) 764 3368. Fax: + 1 (313) 7644292
}

relatively high tensile strength and then cracks along a smooth fracture plane without aggregate pullout, it has been shown that its softening curve has a relatively sharp descent compared to plain concrete, and thus the material is more brittle, with a lower $l_{c h}$. Fibre reinforced concrete, on the other hand, has been shown to have a relatively flat softening curve compared to the plain concrete, and is thus more ductile, with higher $l_{c h}$. Hillerborg ${ }^{2}$ presented the results of theoretical analyses performed by Petersson ${ }^{3}$ and Gustafsson ${ }^{4}$, which showed the ratios $f_{t} / f_{1}$ and $f_{v} / f_{t}$, respectively, as increasing functions of the parameter $l_{c n} / d$, where $f_{\text {, is }}$ the flexural strength of an unreinforced beam, $f_{v}$ is the shear strength of a longitudinally reinforced beam, and $d$ is the beam depth. $l_{c r} / d$ is a structural brittleness parameter, with more brittle behaviour being observed when the material characteristic length decreases or the structural size increases. These analyses show the dependence of structural strengths $f_{f}$ and $f_{v}$ on the material tensile fracture properties $f_{1}$ and $l_{c n}$. However, the tension-softening curve is, in general, too difficult and too time-consuming to measure for practical implementation in routine design and quality control.

Researchers have attempted to use the flexural load. deflection curve rather than the softening curve as a means of quantifying the improved fracture resistance of fibre concrete. The advantage of this procedure is that the test is relatively simple to perform and closely simulates many of the loading conditions imposed on fibre concrete in practical applications. However, the disadvantages of this method are that the curve depends on the specimen size and geometry, and the loading configuration. It is also more difficult to use a complete curve rather than just a single parameter (such as $G_{F}$ or $l_{c h}$ in design. Numerous researchers have proposed using flexural-toughness indexes, which are defined using the flexural load-deflection curve as a means of getting around these problems. Henager ${ }^{5}$ proposed indexes based on the point of first crack on the load. deflection curve. Johnston ${ }^{6}$ proposed indexes $I_{5}, I_{10}$, and $I_{30}$ based on the area under the curve up to certain defined deflection values. Wang and Backer ${ }^{7}$ described new indexes that are more sensitive to the post-peak 
shape of the load-deflection curve. The disadvantages of the previously mentioned indexes are that it is difficult to locate accurately the position of first crack on the load-deflection curve, relatively time-consuming to record a complete load-deflection curve (compared, for example, to measuring only the compression strength), and difficult to use a set of indexes for the purposes of design and quality control. The flexural load-deflection curve can, however, tell us a great deal about material fracture resistance properties.

\section{Research significance}

The aim of this research is to examine how changes in material brittleness can lead to changes in structural behaviour, particularly flexural performance. Material brittleness is varied by reinforcing plain mortar with various fibre types (steel and synthetic) and by using various volume fractions. The possibility of characterising the tensile fracture properties of a nonyielding material like concrete, using only the flexural and first crack splitting tensile strengths, is successfully demonstrated. This is a simple procedure, ideally suited for design purposes, and should encourage engineers to make greater use of both fibre reinforced concrete and high-strength concrete in future practical applications. These research findings can be used to devise a future programme of testing on practical plain concrete and fibre reinforced concrete mixes, the results of which could be used in design codes so that material brittleness may be better accounted for.

\section{Experimental programme}

Four different beam sizes, all with similar geometries, were tested under third.point bending, as shown in Fig 1, to examine the influence of beam size on the flexural strength and flexural load-deflection curve. Plain mortar, as well as mortar reinforced with various volume fractions of steel, aramid, high-modulus polyethylene, and acrylic fibres, were used in the beams to investigate the effects of material fracture resistance on the flexural behaviour. The fibre properties are listed in Table 1. A total of 129 beams (in sets of three nominally identical specimens) were tested to give results for 43 different combinations of beam size, fibre type, and fibre volume fraction. The beam depths used were 63.5, 114, 171 and $228 \mathrm{~mm}(2.5,4.5,6.75$ and 9 in.). A constant mortar mix with a cement:sand:water ratio of $1: 1: 0.4$ by weight was used. The cement was Type III rapid hardening and the sand passed through a \#8 sieve. Volume fractions of $0.5,1.0,1.5$, and 2.0 percent were used with the $25 \mathrm{~mm}$ steel fibres; 1.0 and 2.0 percent with the $50 \mathrm{~mm}$ steel fibres; $0.5,1.0$ and 1.5 percent with the aramid fibres; 1.0 and 2.0 percent with the acrylic fibres; and 1.0 percent with the high-modulus polyethylene fibres. All the materials were added initially to a bladeless mixer and mixing was performed for about three minutes. Superplasticizer was used with the synthetic fibres to ensure adequate workability. All beams were tested perpendicular to the casting direction. The specimens were covered with plastic after casting for about 12 to $14 \mathrm{hr}$ and were then demolded and stored in air at $20^{\circ} \mathrm{C}\left(68^{\circ} \mathrm{F}\right)$ until testing at between 14 and 16 days of age. Complete details of the testing programme are given by Ward. ${ }^{8}$
Table 1 Fibre properties

\begin{tabular}{|c|c|c|c|c|c|c|}
\hline $\begin{array}{l}\text { Fibre } \\
\text { type }\end{array}$ & $\begin{array}{l}\text { Length } \\
\mathrm{mm}\end{array}$ & $\begin{array}{c}\text { Aspect, } \\
\text { ratio } \\
\| / d_{o H}\end{array}$ & $\begin{array}{c}\text { Tensile } \\
\text { strength, } \\
\text { MPa }\end{array}$ & $\begin{array}{l}\text { Modulus, } \\
\text { GPa }\end{array}$ & $\begin{array}{c}\text { Density } \\
\mathrm{g} / \mathrm{cm}^{3}\end{array}$ & Surface \\
\hline Steel & 25.0 & 28.5 & . 1000 & 200 & 79 & Crimped \\
\hline Steel & 500 & 57 & 1000 & 200 & i 79 & Crimped \\
\hline Aramıd & 6.4 & 530 & 2800 & 130 & 145 & Straight \\
\hline Acry:c & 64 & 470 & 400 & 6 & 115 & Straıght \\
\hline $\begin{array}{l}\text { High-modulus } \\
\text { polyethylene }\end{array}$ & 127 & 334 & 2000 & 100 & 097 & Straight \\
\hline
\end{tabular}

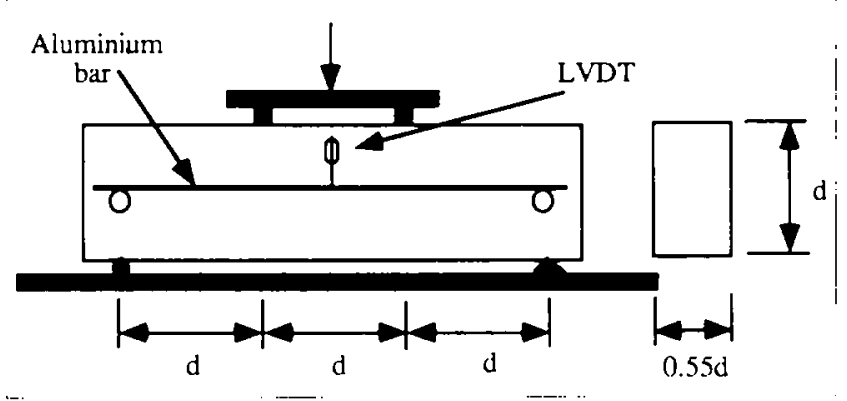

Fig 1 Specimen geometry and loading configuration for flexural test

Testing was carried out in a displacement-controlled testing machine. All beams of a similar size were loaded with similar initial cross-head speeds and the actual speeds were changed in proportion to the beam depth. The initial speed for the $114 \mathrm{~mm}$ ( $4.5 \mathrm{in}$.) beams was $0.6 \mathrm{~mm} / \mathrm{min}(0.024 \mathrm{in} . / \mathrm{min})$. Some time after the maxi. mum load was reached, the loading rate was increased to ensure a reasonable testing time. The load was applied to the top of the beams through two rectangular cross section loading platens placed across the full width of the beam. The width of these platens was 0.11 times the beam depth. $A$ linear variable differential transformer (LVDT) was placed at the centre of each of the three larger sized beams to measure the midspan deflection. All tests were continued until the load dropped below 10 percent of the maximum value. All the plain mortar beams failed suddenly at the maximum load, and so it was not possible to measure the descending branch of the flexural load-deflection curve.

A total of 91 cylinders $[77 \mathrm{~mm}$ (3 in.) diameter x 154 $\mathrm{mm}$ ( 6 in.) long] were also tested to give average values for the compressive strength (average of three tests) and the splitting tensile strength (average of four tests) for the 13 different mixes.

\section{Mortar Ratios}

A mortar mix (rather than concrete) was used in this testing programme to ensure more homogenous specimens than if coarse aggregate were present, especially in the smaller beams. This allowed easier detection of trends in the test data. It was hoped that, by identifying data trends, it would be possible to reduce the scope of a future test programme on practical concrete mixes.

The mortar mix used in this programme does not differ significantly from what might be present in plain concrete, with a design strength of about $40 \mathrm{MPa}(5800$ psi). A possible design mix for a plain concrete 28.day 
Table 2 Flexural, splitting tensile, and compressive strengths of various fibre reinforced mortars

\begin{tabular}{|c|c|c|c|c|c|c|c|c|c|}
\hline \multirow[b]{2}{*}{ Fibre type } & \multirow[b]{2}{*}{$\begin{array}{l}\text { Length, } \\
\mathrm{mm}\end{array}$} & \multirow[b]{2}{*}{$\begin{array}{c}V_{f} \\
\text { percent }\end{array}$} & \multicolumn{4}{|c|}{ Flexural strength } & \multicolumn{2}{|c|}{ Splitting tensile strength } & \multirow{2}{*}{$\begin{array}{c}\text { Compressive } \\
\text { strength } \\
\mathrm{MPa}\end{array}$} \\
\hline & & & $\begin{array}{c}d=63.5 \\
\mathrm{MPa}\end{array}$ & $\begin{array}{c}d=114 \\
\mathrm{MPa}\end{array}$ & $\begin{array}{c}d=171 \\
\mathrm{MPa}\end{array}$ & $\begin{array}{c}d=228 \\
\mathrm{MPa}\end{array}$ & $\begin{array}{c}\text { Crack, } \\
\mathrm{MPa}\end{array}$ & $\underset{\mathrm{MPa}}{\text { Maximum }}$ & \\
\hline Plain mortar & & 0 & 30 & 26 & 23 & 24 & 29 & 2.9 & 57.0 \\
\hline Aramid & 64 & 05 & 49 & 4.1 & 40 & 39 & 4.2 & 4.2 & 52.1 \\
\hline Aramid & 64 & 10 & 55 & 5.1 & 4.7 & 5.1 & 4.4 & 4.4 & 50.3 \\
\hline Aramid & 64 & 1.5 & 69 & 61 & 60 & 55 & 4.6 & 46 & 45.5 \\
\hline Steel & 25 & 0.5 & 3.6 & 35 & 35 & 3.5 & 36 & 56 & 589 \\
\hline Steel & 25 & 1.0 & 5.1 & 5.4 & 4.9 & 4.7 & 3.9 & 6.0 & 62.6 \\
\hline Steel & 25 & 15 & 64 & 62 & 5.7 & 55 & 48 & 59 & 597 \\
\hline Steel & 25 & 2.0 & 70 & 7.0 & 6.6 & 6.6 & 48 & 5.6 & 57.0 \\
\hline Steel & 50 & 1.0 & & 7.4 & & 6.2 & 4.3 & 6.2 & 54.1 \\
\hline Steel & 50 . & 2.0 & & 89 & & 7.8 & 56 & 76 & \\
\hline Acrylic & 64 & 1.0 & & 40 & & 3.4 & 43 & 43 & 45.3 \\
\hline Acrylic & 64 & 2.0 & & 3.7 & & 3.5 & 3.6 & 36 & 33.0 \\
\hline $\begin{array}{l}\text { High-modulus } \\
\text { polyethylene }\end{array}$ & 12.7 & 1.0 & & 89 & & 7.7 & 3.2 & 64 & 457 \\
\hline
\end{tabular}

strength of $40 \mathrm{MPa}$ and slump in the range 60 to 180 $\mathrm{mm}$ is as follows: cement $488 \mathrm{~kg} / \mathrm{m}^{3}$; water 195 $\mathrm{kg} / \mathrm{m}^{3}$; fine aggregate $[<5.5 \mathrm{~mm}] 677 \mathrm{~kg} / \mathrm{m}^{3}$; and coarse aggregate $\left[5\right.$ to $20 \mathrm{~mm}$ ] $1015 \mathrm{~kg} / \mathrm{m}^{3}$.

The cement:sand:water ratio for this mix is $1: 1.39: 0.4$, compared to a ratio of $1: 1: 0.4$ used in the test programme. The volume fraction of coarse aggregate in the mix would be about 40 percent (assuming a coarse aggregate relative density of 2.6). If a 1 percent volume fraction of fibres were added to this mix, then the true volume fraction of fibres in the mortar alone would be $1 / 0.6=1.67$ percent. This is why higher overall fibre volume fractions should be used for tests on mortar than for tests on concrete specimens.

\section{Test results and discussion}

\section{Compressive strength}

The compressive strength of each material is listed in Table 2. Fig 2 illustrates the effects of fibre type and volume fraction on the compressive strength. Steel fibres increase the strength slightly, with a maximum increase of 10 percent being observed at a one percent volume fraction. The strength increase may be due to

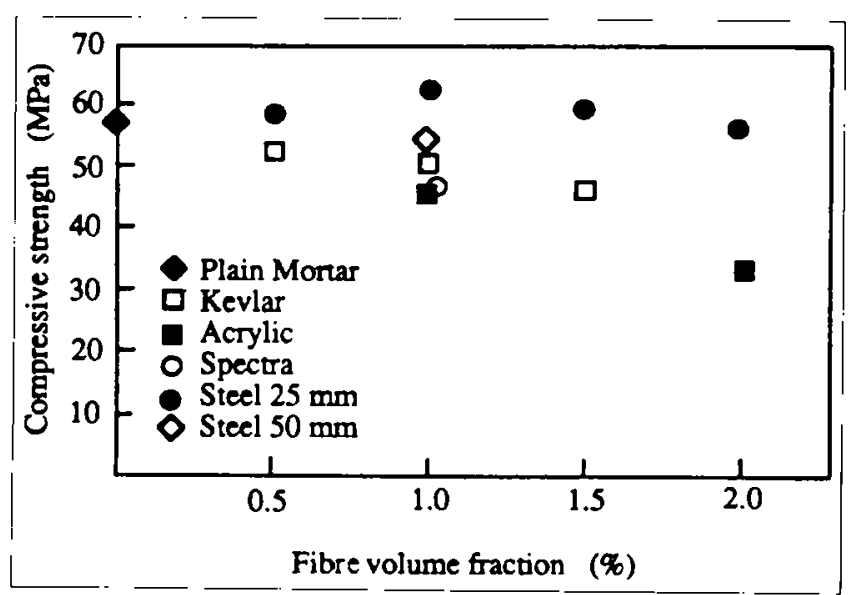

Fig 2 Effect of fibre reinforcement on compressive strength $(1 \mathrm{MPa}=145$ psi) dowel-like resistance of relatively stiff steel fibres that bridge crack-like defects where compressive failure initiates. Synthetic fibres generally lead to decreasing strength as the fibre volume fraction is increased. Decreases of the order of 20 percent were noted at a volume fraction of 1 percent. These strength reductions may be related to porosity increases due to compaction difficulties with high aspect ratio flexible fibres.

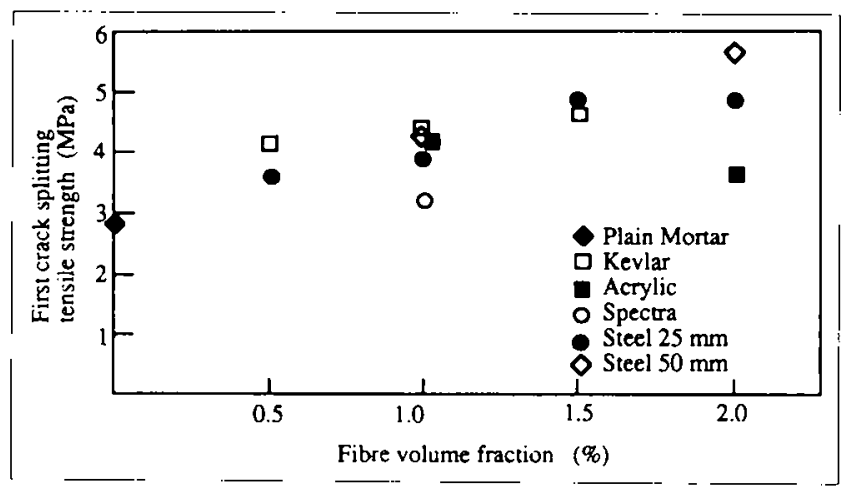

Fig 3 Effect of fibre reinforcement on the first crack splitting tensile strength $(1 \mathrm{MPa}=145 \mathrm{psi})$

\section{Splitting tensile strength}

The first crack and maximum splitting tensile strengths are listed in Table 2. Fig 3 illustrates the effects of fibre type and volume fraction on the first crack strength. This strength was calculated from the load at which the first visible crack appeared across the cylinder. In many cases, the appearance of the crack was accompanied by a low popping sound. In general, the cracking tensile strength increases with fibre volume fraction. Aramid fibres give much higher cracking strength than high. modulus polyethylene, probably because their higher bond strength with mortar. Due to their relatively good bond strength and high aspect ratio the $6.4 \mathrm{~mm}$ aramid fibres can provide similar cracking strengths to those provided by the $25 \mathrm{~mm}$ steel fibres. A 2 percent volume fraction of acrylic fibres provides a low tensile strength, mainly because of compaction problems with resulting 
high porosity. The maximum loads recorded in the splitting tests are not considered meaningful because of unknown stress distribution after cracking. It is interesting, however, that for the plain mortar and acrylic and aramid fibre mortar specimens, the first crack and maximum loads correspond, whereas there are substantial differences (up to 100 percent) for the high modulus polyethylene and steel fibre mortars, due to the greater ability of these fibres to transfer relatively high stresses after composite cracking.

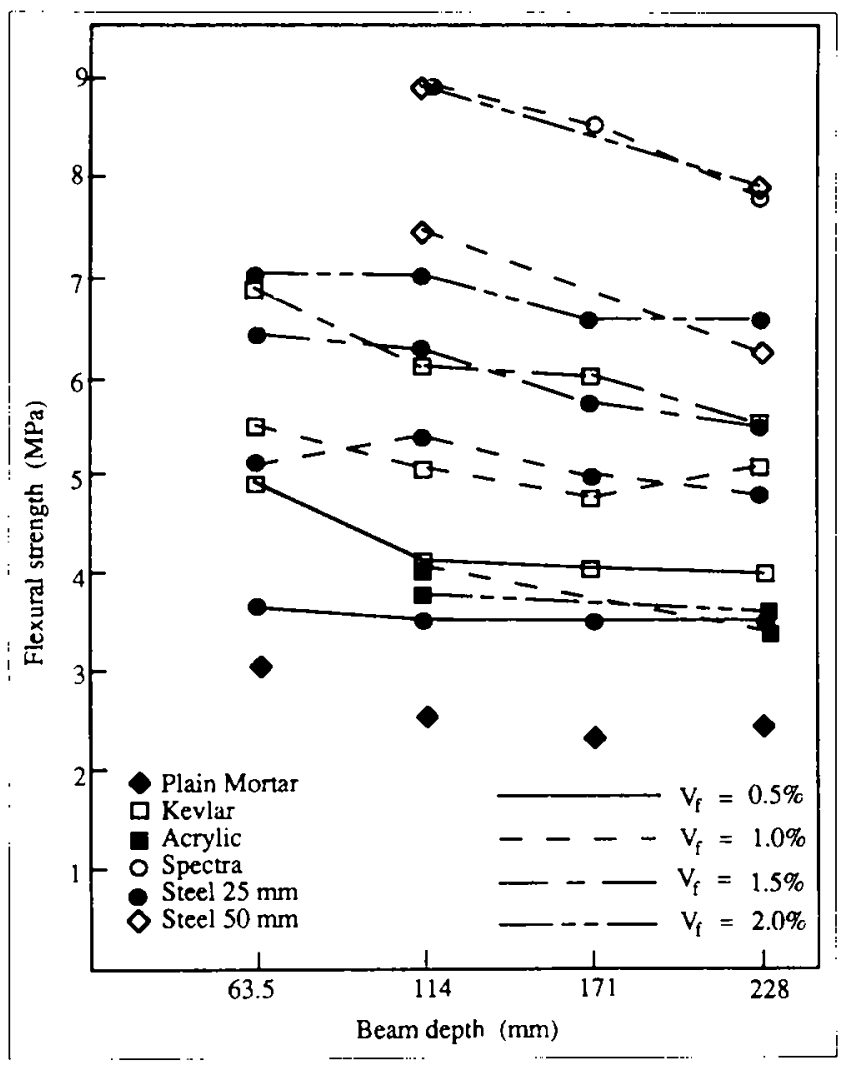

Fig 4 Influence of beam size on flexural strength $(1 \mathrm{MPa}=145 \mathrm{psi})$

\section{Flexural strength}

The flexural strengths for each material and each beam size (corrected for the effects of loading fixtures and beam self-weight) are listed in Table 2. Figure 4 illustrates similar trends of decreasing strength as beam size increases for all the materials. Other investigators related strength reductions to the volume of material within a probable failure zone. For beams with similar geometries, the material volume is a function of the beam depth and, for these cases, Johnson ${ }^{9}$ found the strength of plain concrete and steel fibre concrete beams approximately proportional to $d^{-03}$; Akihama, Suenaga, and Nakagawa ${ }^{10}$ found the strength of carbon fibre reinforced concrete beams approximately proportional to $d^{-0.374}$; and Torrent and Brooks ${ }^{11}$ found the strength of plain concrete beams approximately proportional to $d^{-0.123}$. The flexural strength values shown in Figure 4 decrease, on average, in proportion to $d^{-0.13}$. Far less dependence on material volume is exhibited than that proposed by Johnston or Akihama. The reasons for this may lie with the loading fixtures, material type, curing process, or effects of beam self-weight.

Petersson's analytical results ${ }^{3}$, showing decreasing

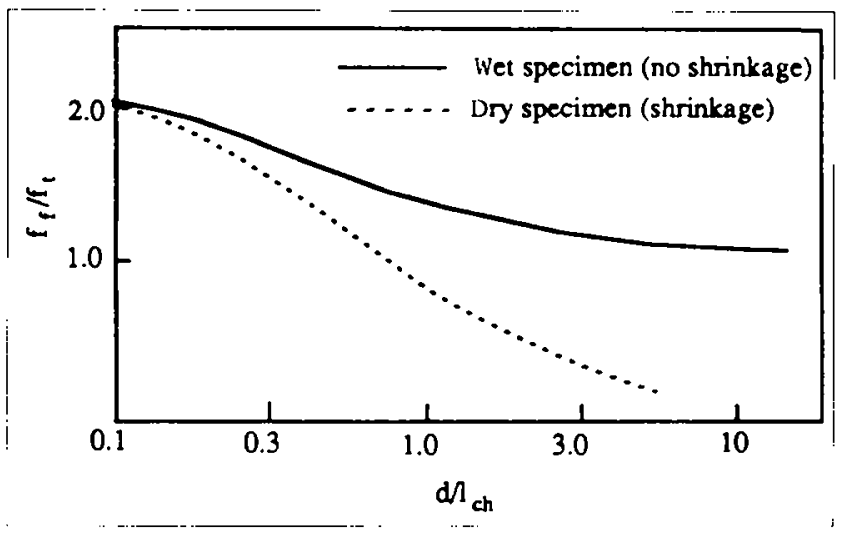

Fig 5 Theoretical curves relating the $f_{f} / f_{\text {, ratio to the }}$ $d / l_{c h}$ ratio calculated using the fictitious crack model

$f_{t} / f_{l}$ ratios as the parameter $d / l_{c h}$ increased, are summarized in Figure 5 . These results are based on a fracture mechanics approach: the size dependence of structural strength stems from the fact that elastic energy is stored and released throughout the beam at a rate proportional to the beam volume (for similar geometries), whereas the energy absorption rate across the critical fracture plane only increases in proportion to the beam cross section size. These results are not exactly applicable to concrete because they are based on an assumed linear elastic stress-strain curve, whereas the true curve shows significant nonlinearity and inelastic deformations. Assuming a Weibull distribution for concrete strengths also leads to a structural size effect because of a greater chance of a weaker section in a larger specimen. To fully understand the size dependence of structural strength, it is necessary to consider energy absorption and release rates in conjunction with the Weibull strength distribution. Ward ${ }^{8}$ gives a short discussion of this approach and shows some typical results.

The theoretical results from Petersson ${ }^{3}$ presented in Figure 5 suggest that the flexural strength depends on both the tensile strength and the material characteristic length. Figure 6 illustrates representations of typical tension softening curves for the materials used in this

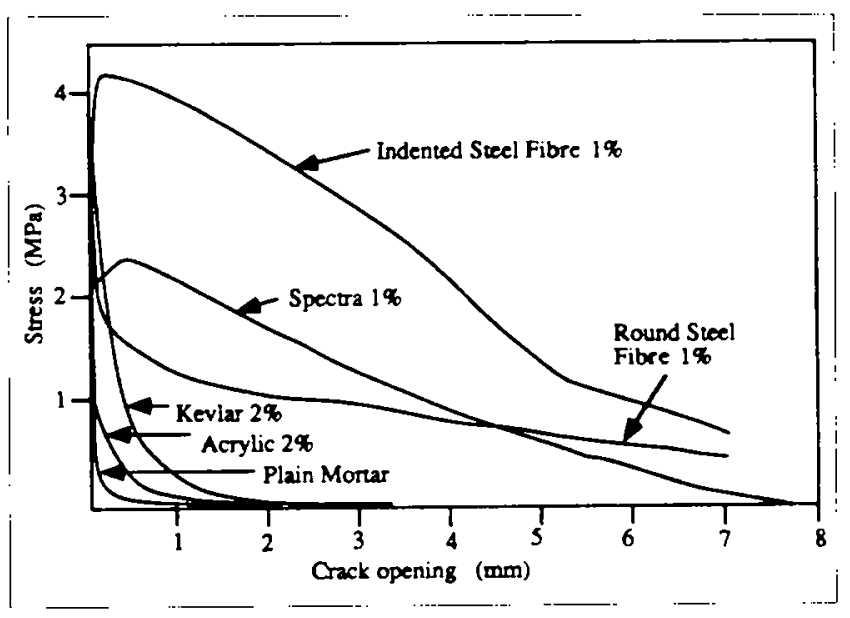

Fig 6 Typical tension-softening curves of mortars reinforced with various fibres 
programme. The plain mortar and synthetic fibre mortar curves were measured in earlier testing programmes 12.13 , using mortar with a cement:sand:water ratio of 1:1:0.5 and the same fibres used in this testing programme. The steel fibre mortar curves are taken from results presented by Hillerborg ${ }^{14}$. It may be expected that the $25 \mathrm{~mm}$ steel fibres used in this testing programme have similar shaped $\sigma-\delta$ curves to that shown for the round steel fibres, and the $50 \mathrm{~mm}$ fibres have similar shaped curves to that shown for the indented steel fibres. Hillerborg ${ }^{14}$ defined an effective $G_{F}^{\prime}$ and $l_{c h}^{\prime}$, based on a continuation of the initial slope of the softening curve as a straight line down to meet $\sigma=0$, and he suggested that the $f_{f} / f_{t}$ ratio was related to $l_{c h}^{\prime}$. He considered the area under the softening curve at large crack openings to have little influence on the maximum beam strength. If an effective $l_{c h}^{\prime}$ was calculated, based on the softening curves in Figure 6, the plain mortar would have the lowest value, the acrylic fibre mortar would be next lowest, the aramid and $25 \mathrm{~mm}$ steel fibre mortars would give the next lowest values, and the $50 \mathrm{~mm}$ steel and high-modulus polyethylene fibre mortars would have the highest values. The effective characteristic length would increase as fibre volume fraction increased and the material became less brittle. Figure 7 shows the $f_{t} / f_{t}$ ratios for each fibre type and volume fraction, calculated using the flexural strengths of the $114 \mathrm{~mm}$ beams. Direct correlation between the trend of increasing $f_{f} / f_{t}$ ratios and increasing material characteristic lengths just mentioned can be seen. This confirms the dependence of flexural strength on material brittleness, as well as on tensile strength.

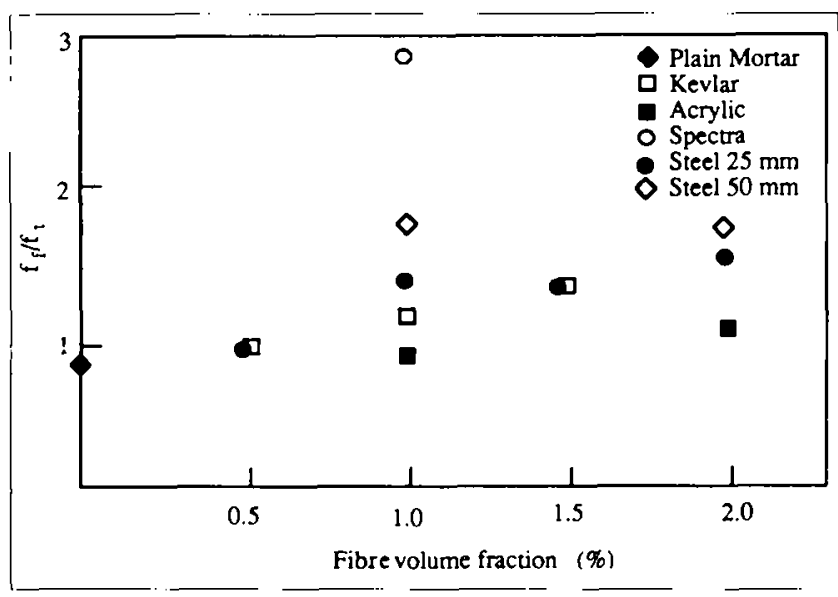

Fig 7 Effect of fibre reinforcement on the ratio between flexural and splitting tensile strengths

The very high $f_{f} / f_{t}$ ratio of the high-modulus polyethylene fibre mortar may be explained as follows. Due to the relatively low tensile cracking strength of this material, a flexural crack formed at the bottom of the beam at a relatively small load in the flexural test. However, because of the relatively flat initial slope of the softening curve, with perhaps some initial stress increase as the fibres are stretched after the composite cracks, the load continued to increase after the flexural cracks developed. Subsequently, a number of cracks formed in the high-moment central span zone. On a macroscopic scale, the behaviour was almost like the yielding of steel once the elastic bending moment capacity is passed. This multiple cracking allowed deformations to exist within the beam that were compatible with developing relatively high tensile stresses over a large proportion of the beam depth. The theoretical limit of the $f_{f} / f_{\text {t }}$ ratio is 3.0 if the tensile strength is developed over the full beam depth, and an infinitesimal compression zone exists at the top of the beam. The $f_{f} / f_{\text {, }}$ ratio of the $114 \mathrm{~mm}$ high-modulus polyethylene fibre beams is 2.78 .

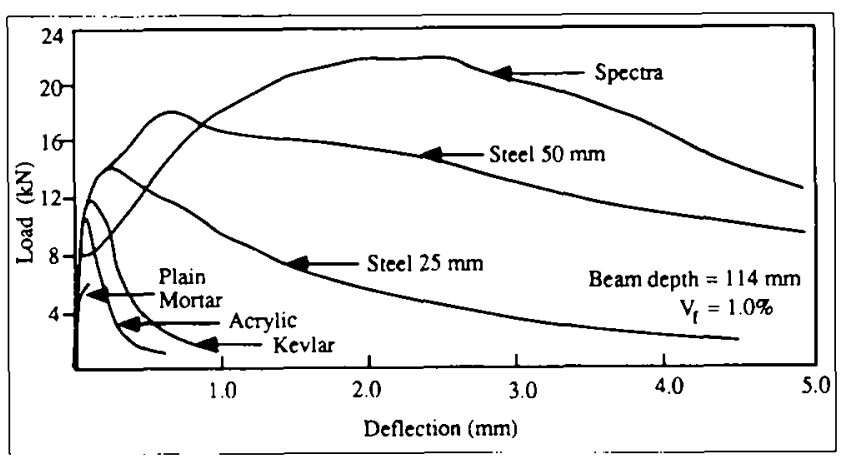

Fig 8 Flexural load-deflection curves for mortars reinforced with various fibre types; $(1 \mathrm{kN}=$ 224.8 (bs)

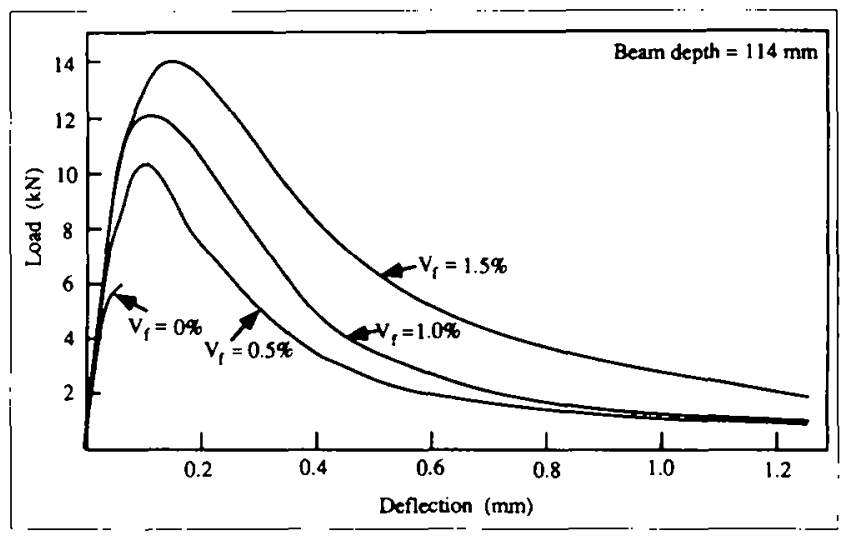

Fig 9 Flexural load-deflection curves for keular fibre reinforced mortar beams $(1 \mathrm{~mm}=0.0394$ in.; $1 \mathrm{kN}=224.8(\mathrm{bs})$

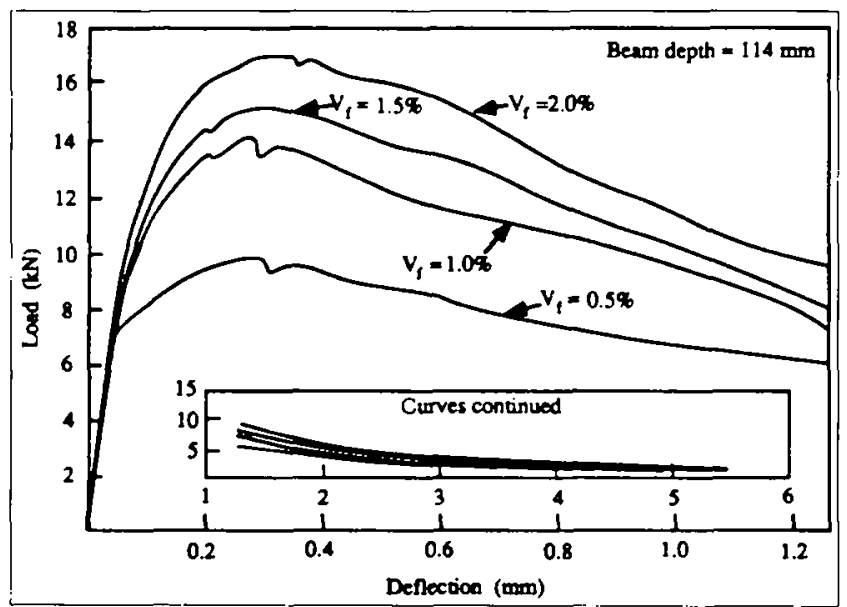

Fig 10 Flexural load-deflection curves for steel fibre $(25$ $\mathrm{mm}$ ) reinforced mortar beams; $(1 \mathrm{kN}=224.8$ (bs) 
Flexural load-deflection curves

Figure 8 shows typical flexural load-deflection curves for each fibre type. Due to inadequate machine stiffness, it was not possible to measure the descending branch of the plain mortar curve. The aramid and acrylic fibre mortars show relatively sharp drops from the peak load. This is due to the relative shortness of these fibres and also to the fact that these fibres tend to form rod-like bundles in the matrix around which the crack propagates, thus giving a higher tensile strength but not giving much fibre pullout. The longer steel fibres show a much more gradual fall-off in load capacity as they pull out of the matrix. The very large deflection in the high-modulus polyethylene fibre mortar beam at the maximum load is due to widespread multiple cracking. The initial correspondence of all the curves is consistent with the generally held view that low-volume fractions of short fibre reinforcement do not significantly change the composite behaviour prior to matrix micro. cracking. 15.16

Figures 9 and 10 show the effects of fibre volume fraction on the flexural load-deflection curves for the aramid and $25 \mathrm{~mm}$ steel fibres. The initial linear elastic part of the curves before matrix microcracking does not change with fibre volume fraction. Energy-absorption capacity increases with fibre-volume fraction. This is because of an increase in the inelastic energy absorbed throughout the beam and also because of the fracture energy absorbed across the critical fracture plane. The higher tensile strength ensures larger stresses and strains and the higher flexural strength ensures more material being stressed beyond the elastic limit. The increase in fracture energy stems from a greater number of fibres bridging the crack and a more tortuous crack propagation path as the volume fraction increases.

Figures 11 and 12 illustrate the influence of beam size on the normalized load versus normalized deflection curves for the aramid and $25 \mathrm{~mm}$ steel fibres. The normalized load is a measure of the flexural stresses in the beam and is defined as $6 M / b d^{2}$ where $M$ is the bending moment along the beam central span and $b$ is the beam width. The normalized deflection corresponds to the midspan deflection divided by the beam depth, and is a measure of the average strains on the beam. These curves are somewhat analogous to the stress versus normalized displacement (average strain) curves obtained from a direct tension test. In the direct tension test, the material initially strains uniformly throughout its length. At the maximum load, a localized fracture zone develops with subsequent increases in deformation within this zone, and decreases in deformation due to elastic rebound outside this zone ${ }^{17}$. The shape of the descending curve is thus dependent on the relative magnitude of these two deformation changes which, in turn, depends on specimen length, ie a longer specimen producing a sharper drop in the curve after maximum load. Increasing the beam size in a flexural test has a somewhat similar influence on the stress-normalized deflection curve.

The total area under the load-deflection curve is indicative of the energy absorbed by the beam. The coincidence of the initial linear elastic parts of the stress. normalized deflection curves in Figures 11 and 12 confirms that the rate of elastic energy absorption is proportional to beam volume, for similar geometries.

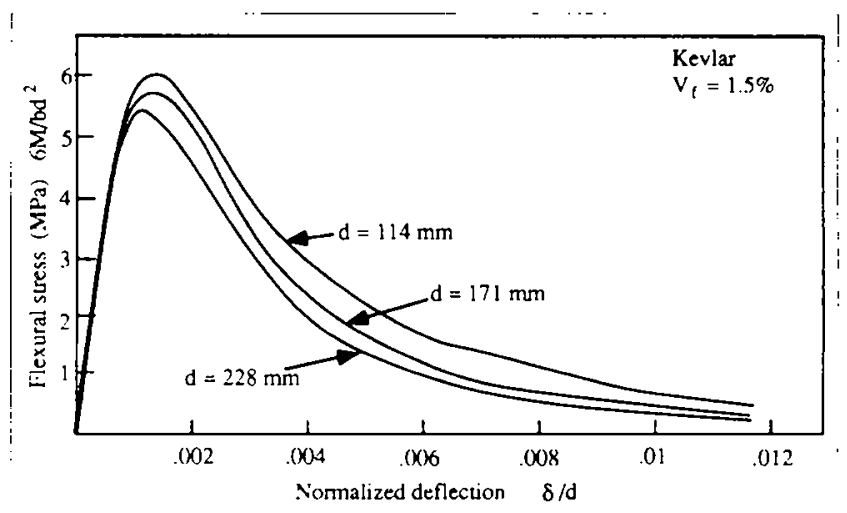

Fig 11 Flexural stress versus normalized deflection for different beam sizes of keular fibre reinforced mortar; $(1 \mathrm{MPa}=145 \mathrm{psi})$

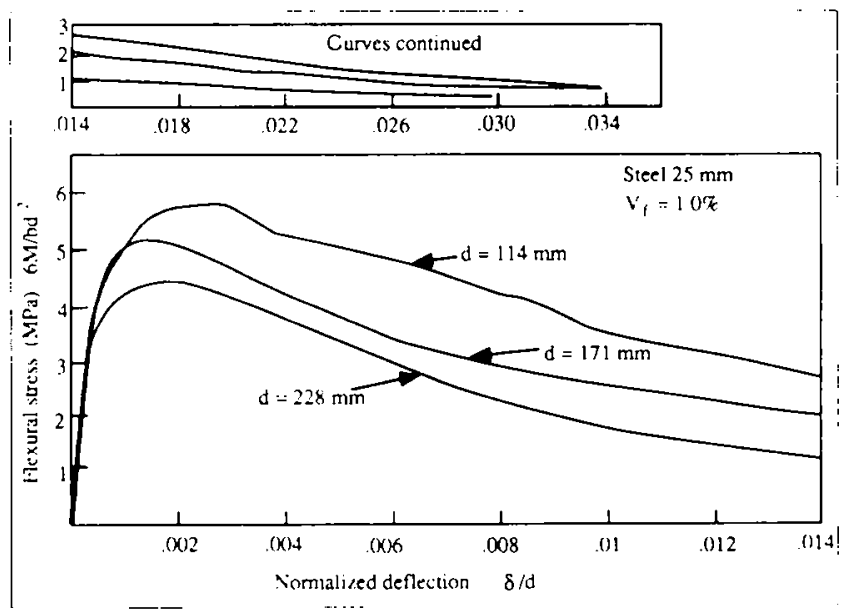

Fig 12 Flexural stress versus normalized deflection for different beam sizes of steel fibre reinforced mortar; $(1 \mathrm{MPa}=145 \mathrm{psi}$ )

After matrix microcracking initiates, inelastic energy is absorbed throughout the more highly stressed parts of the beam, at a rate proportional to the beam volume. However, energy absorbed by the critical fracture zone is proportional to the beam cross-sectional size, and this partly accounts for the size dependence of the normalized load deflection curves. A second contribution to the size-effect can be attributed to the reduced flexural strength as beam size increases, resulting in less material (proportionally) being stressed beyond its elastic limit and, thus, less inelastic energy being absorbed per unit volume of beam. It is possible to express qualitatively the energy-absorption capacity of a beam in flexure by:

$$
U=\mathrm{k}_{1} b d^{2}+G_{F} b d
$$

where $k_{1}$ accounts for energy absorbed per unit beam volume away from the critical fracture zone. The factor $k_{1}$ may be expected to be a decreasing function of beam size. Normalization of Equation (1) leads to:

$$
U / b d^{2}=k_{1}+G_{F} / d
$$

which illustrates normalized energy absorption as a decreasing function of beam size. 
Table 3 Flexural toughness indexes of mortars reinforced with various fibre types

\begin{tabular}{|c|c|c|c|c|c|c|c|c|c|c|}
\hline Fibre type & Length, mm & $V_{f}$ percent & $\begin{array}{c}\text { Beam depth, } \\
\mathrm{mm}\end{array}$ & $I_{5}$ & $I_{10}$ & $1_{30}$ & $t_{50}$ & $T_{\max }$ & $T_{50}$ & $\begin{array}{c}T_{10} \\
\mathrm{kN} / \mathrm{m}\end{array}$ \\
\hline Plaın mortar & & 0 & $\begin{array}{l}114 \\
171 \\
228\end{array}$ & & & & & $\begin{array}{l}1.8 \\
1.3 \\
12\end{array}$ & & \\
\hline Aramid & 6.4 & 0.5 & $\begin{array}{l}114 \\
171 \\
228\end{array}$ & $\begin{array}{l}6.9 \\
6.9 \\
67\end{array}$ & $\begin{array}{l}149 \\
14.8 \\
12.9\end{array}$ & $\begin{array}{l}33.9 \\
31.3 \\
21.9\end{array}$ & $\begin{array}{l}42.0 \\
37.4 \\
24.2\end{array}$ & $\begin{array}{l}3.9 \\
3.1 \\
2.5\end{array}$ & $\begin{array}{r}13.6 \\
11.1 \\
8.0\end{array}$ & $\begin{array}{l}0.53 \\
0.70 \\
0.53\end{array}$ \\
\hline Aramid & 6.4 & 1.0 & $\begin{array}{l}114 \\
171 \\
228\end{array}$ & $\begin{array}{l}7.8 \\
74 \\
7.7\end{array}$ & $\begin{array}{l}17.7 \\
16.7 \\
17.2\end{array}$ & $\begin{array}{l}41.3 \\
352 \\
33.9\end{array}$ & $\begin{array}{l}49.2 \\
412 \\
37.6\end{array}$ & $\begin{array}{l}4.5 \\
3.4 \\
3.5\end{array}$ & $\begin{array}{r}111 \\
10.0 \\
90\end{array}$ & $\begin{array}{l}0.61 \\
0.76 \\
0.89\end{array}$ \\
\hline Aramid & 6.4 & 1.5 & $\begin{array}{l}114 \\
171 \\
228\end{array}$ & $\begin{array}{l}79 \\
77 \\
78\end{array}$ & $\begin{array}{l}19.4 \\
19.6 \\
18.7\end{array}$ & $\begin{array}{l}550 \\
54.6 \\
461\end{array}$ & $\begin{array}{l}708 \\
67.8 \\
540\end{array}$ & $\begin{array}{l}5.1 \\
5.4 \\
3.9\end{array}$ & $\begin{array}{l}12.9 \\
10.7 \\
11.0\end{array}$ & $\begin{array}{c}1.0 \\
1.34 \\
148\end{array}$ \\
\hline Steel & 25 & 0.5 & $\begin{array}{l}114 \\
171 \\
228\end{array}$ & $\begin{array}{l}6.5 \\
6.8 \\
6.6\end{array}$ & $\begin{array}{l}12.0 \\
122 \\
13.0\end{array}$ & $\begin{array}{l}36.4 \\
34.7 \\
36.0\end{array}$ & $\begin{array}{l}58.8 \\
52.8 \\
53.2\end{array}$ & $\begin{array}{l}7.0 \\
2.6 \\
2.4\end{array}$ & $\begin{array}{l}66.5 \\
42.0 \\
40.5\end{array}$ & $\begin{array}{l}2.26 \\
2.57 \\
291\end{array}$ \\
\hline Steel & 25 & 1.0 & $\begin{array}{l}114 \\
171 \\
228\end{array}$ & $\begin{array}{l}7.5 \\
7.1 \\
7.4\end{array}$ & $\begin{array}{l}17.2 \\
17.9 \\
16.0\end{array}$ & $\begin{array}{l}553 \\
48.5 \\
46.8\end{array}$ & $\begin{array}{l}88.8 \\
83.1 \\
69.9\end{array}$ & $\begin{array}{r}10.4 \\
6.5 \\
5.2\end{array}$ & $\begin{array}{l}40.5 \\
31.3 \\
28.2\end{array}$ & $\begin{array}{l}3.05 \\
3.32 \\
3.00\end{array}$ \\
\hline Steel & 25 & 1.5 & $\begin{array}{l}114 \\
171 \\
228\end{array}$ & $\begin{array}{l}8.0 \\
81 \\
7.5\end{array}$ & $\begin{array}{l}19.9 \\
20.4 \\
18.1\end{array}$ & $\begin{array}{l}75.2 \\
70.7 \\
59.4\end{array}$ & $\begin{array}{r}116.0 \\
111.7 \\
924\end{array}$ & $\begin{array}{l}8.7 \\
7.5 \\
7.0\end{array}$ & $\begin{array}{l}37.0 \\
31.0 \\
30.0\end{array}$ & $\begin{array}{l}370 \\
4.20 \\
450\end{array}$ \\
\hline Stee & 25 & 2.0 & $\begin{array}{l}114 \\
171 \\
228\end{array}$ & $\begin{array}{l}7.8 \\
7.9 \\
80\end{array}$ & $\begin{array}{l}19.0 \\
19.6 \\
20.7\end{array}$ & $\begin{array}{l}79.8 \\
68.6 \\
68.0\end{array}$ & $\begin{array}{r}122.2 \\
109.0 \\
91.3\end{array}$ & $\begin{array}{r}10.7 \\
7.2 \\
6.9\end{array}$ & $\begin{array}{l}35.0 \\
32.2 \\
24.4\end{array}$ & $\begin{array}{l}4.26 \\
4.35 \\
5.03\end{array}$ \\
\hline Steet & 50 & 1.0 & 114 & 64 & 15.4 & 64.5 & 123.0 & 22.6 & 1061 & 13.90 \\
\hline Steel & 50 & 2.0 & 114 & 6.9 & 17.3 & 75.7 & 1460 & 223 & 992 & 18.20 \\
\hline Acrylic & 6.4 & 1.0 & $\begin{array}{l}114 \\
228\end{array}$ & 6.9 & 13.0 & 214 & & $\begin{array}{l}2.5 \\
1.8\end{array}$ & 8.0 & 0.26 \\
\hline Acrylic & 6.4 & 2.0 & $\begin{array}{l}114 \\
228\end{array}$ & $\begin{array}{l}6.4 \\
5.9\end{array}$ & $\begin{array}{r}12.2 \\
9.9\end{array}$ & $\begin{array}{l}253 \\
136\end{array}$ & & $\begin{array}{l}2.8 \\
25\end{array}$ & $\begin{array}{r}12.0 \\
6.4\end{array}$ & $\begin{array}{l}0.36 \\
0.36\end{array}$ \\
\hline $\begin{array}{l}\text { High-modulus } \\
\text { polyethylene }\end{array}$ & 12.7 & 1.0 & 114 & 6.2 & 130 & 502 & 947 & 66.6 & 970 & 1660 \\
\hline
\end{tabular}

\section{Flexural toughness indexes}

The $I_{5}, I_{10}$ and $I_{30}$ indexes defined by Johnston were calculated for each material and beam size. A full description of these calculations and results is given by Ward. ${ }^{8}$ Table 3 lists the calculated values. A complete set of indexes can give a good idea of the general shape of the load-deflection curve. However, these indexes do not efficiently provide a characterization of material behaviour or the flexural load curve.

Three new flexural toughness indexes are now defined which effectively characterize flexural performance. Ward ${ }^{8}$ described these indexes in greater detail. Table 3 lists each index value for all the materials and each beam size. $T_{\max }$ is defined as the beam deflection at maximum load divided by the deflection, at first crack. It is somewhat analogous to the ductility ratio $\phi_{u} / \phi_{y}$ used with reinforced concrete beams, and gives an idea of the amount of inelastic deformation and multiple cracking that occurs before the ultimate load is reached. The influence of beam size and fibre-volume fraction on $T_{\max }$ is illustrated in Figure 13. In general, the index value increases as fibre volume fraction increases and beam size decreases.

$T_{50}$ is defined as the deflection when load drops to 50 percent of the maximum value divided by the deflection which would be observed at a similar load on the ascending part of the load-deflection curve, if the beam behaved linear elastically up to this point. This parameter is somewhat analogous to the beam brittleness parameter $l_{c h} / d$ used by Hillerborg. It reflects a beam's ability to absorb energy by inelastic deformation relative to the rate at which it stores or releases elastic energy. Figure 14 illustrates the influence of beam size and fibre-volume fraction on $T_{50}$. For a given fibre type, the fibre-volume fraction does not significantly influence $T_{50}$. This is because flexural strength and energy capacity increase in similar proportions. It is interesting to compare this behaviour with that of plain concrete when it is changed from ordin. ary strength to high strength. The proportional increase in strength is greater than the proportional increase in energy capacity, leading to more brittle behaviour.

$T_{10}$ is defined as the total area under the load. deflection curve up to the point where the load drops to 10 percent of the maximum value, divided by the beam cross-sectional area. It correlates approximately with the total energy-absorption capacity of the beams. If inelastic energy absorption outside the fracture zone is small, then it correlates with the fracture energy. Figure 15 illustrates the influence of beam size and fibre. 


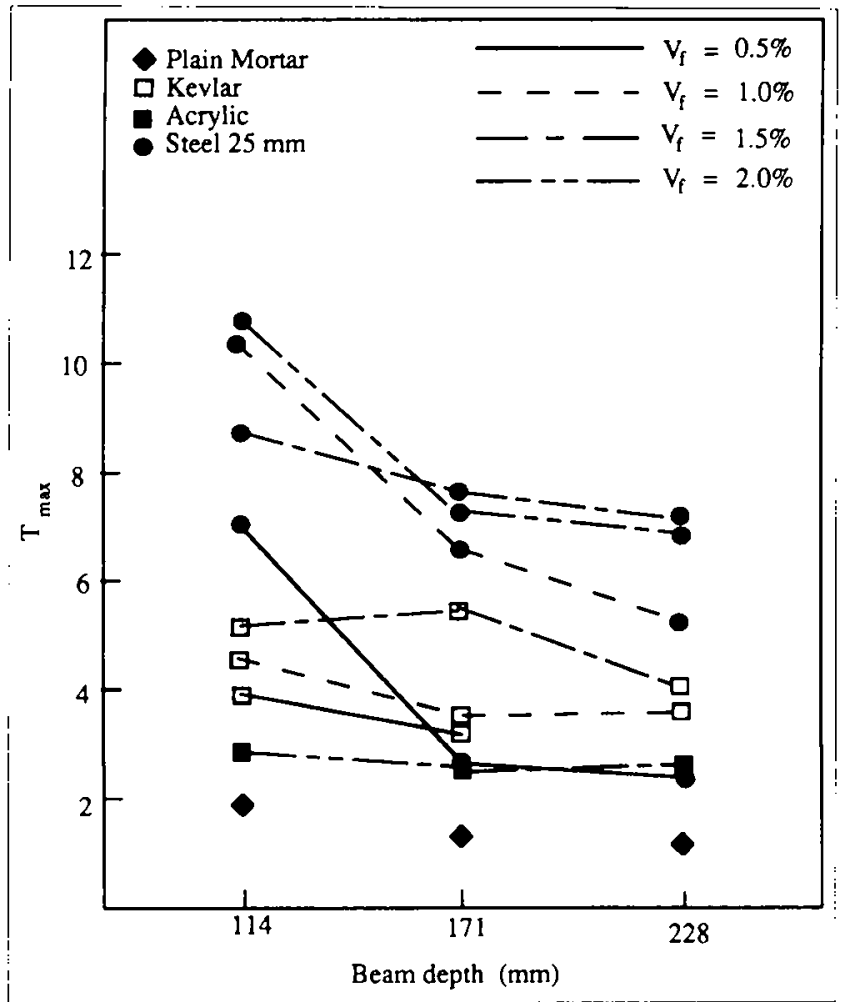

Fig 13 Influence of beam size on flexural toughness index $\mathrm{T}_{\max }$

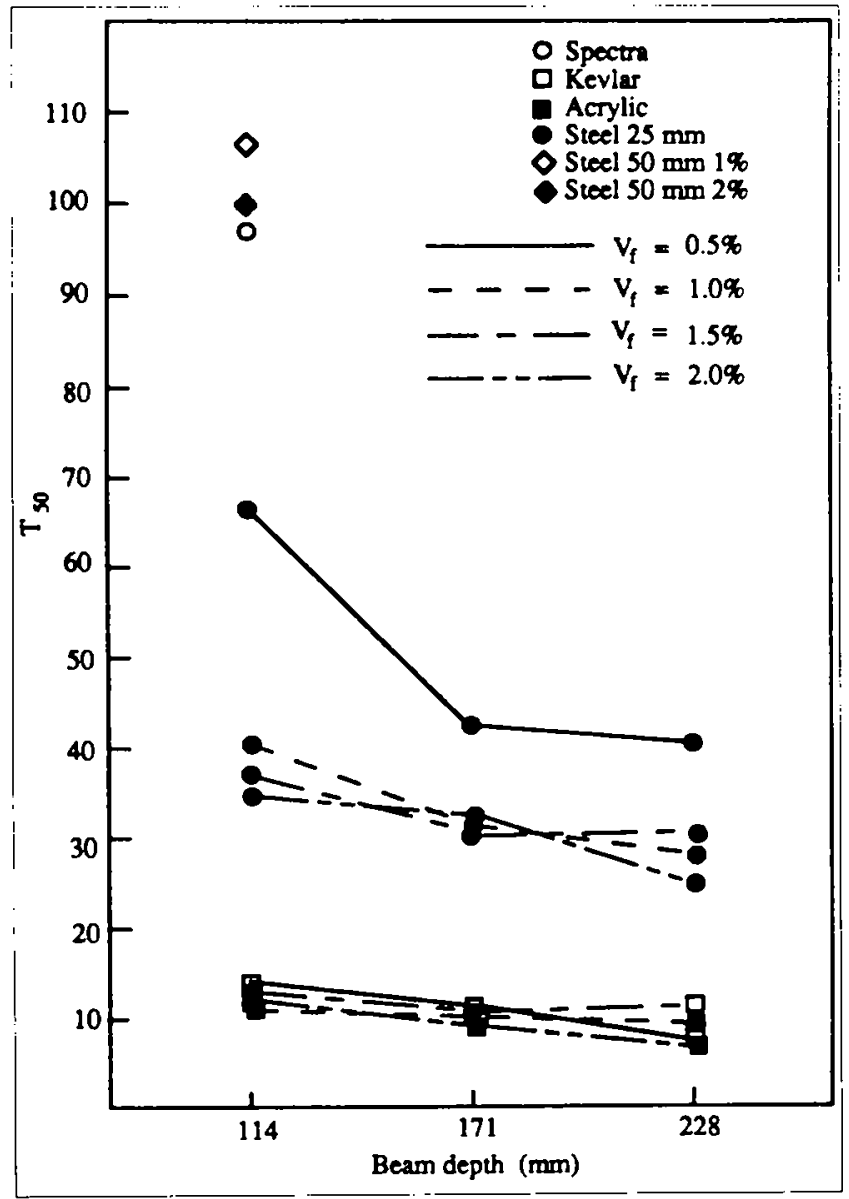

Fig 14 Influence of beam size on flexural toughness index $\mathrm{T}_{50}$

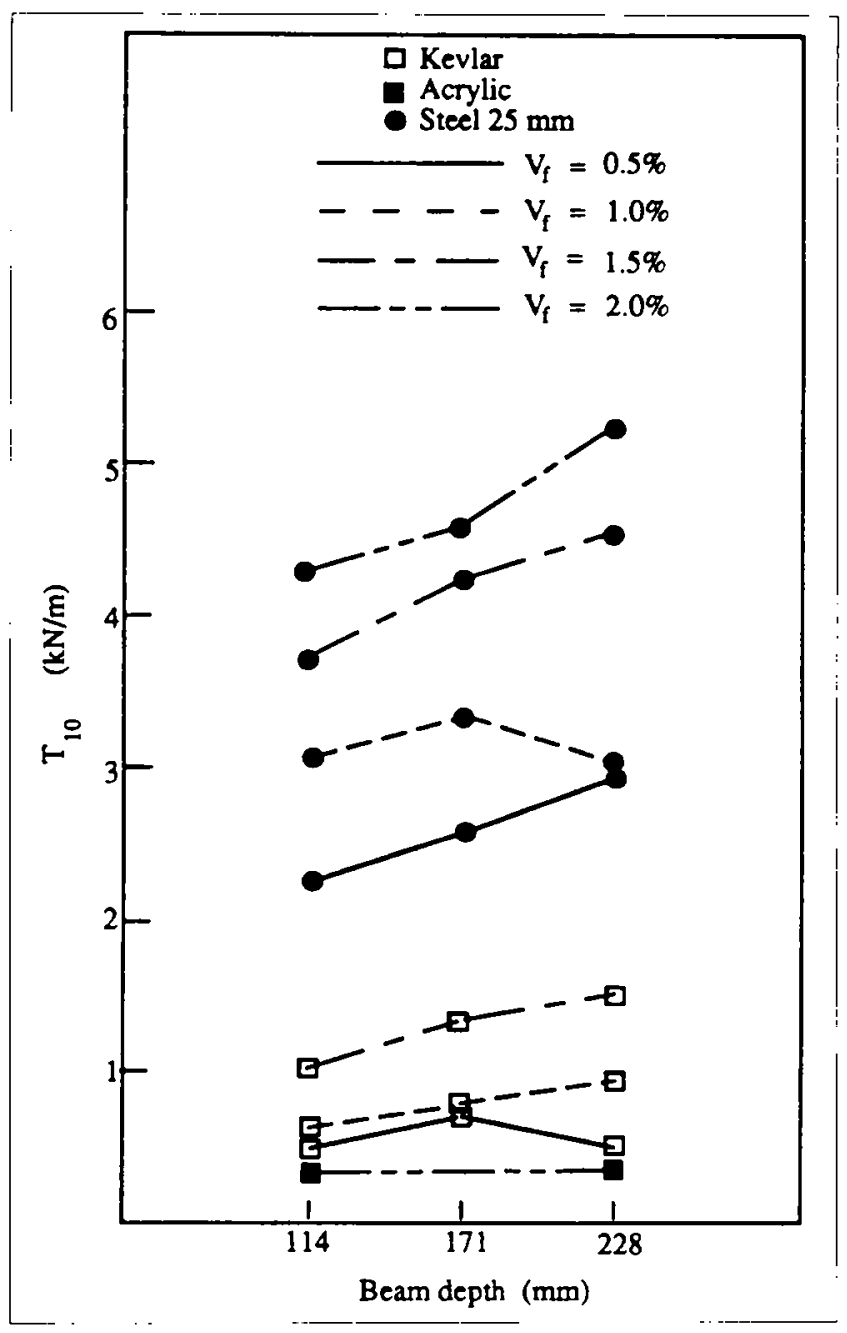

Fig 15 Influence of beam size on flexural toughness index $\mathrm{T}_{10}(1 \mathrm{kN} / \mathrm{m}=5.7 \mathrm{lb} / \mathrm{in}$. $)$

volume fraction on $T_{10}$. As beam size increases, so does the ratio between distributed inelastic energy absorbed (proportional to beam volume) and energy absorbed (proportional to beam section size), and this more than compensates for energy-absorption losses due to lower flexural strengths, resulting in increasing $T_{10}$ values as beam size increases. The $T_{10}$ value also reflects the increases in energy-absorption capacity as the fibre-volume fraction is increased.

\section{Simple estimates of flexural toughness}

The ability of the flexural load-deflection curve to distinguish the behaviour of mortar reinforced with various fibre types and volume fractions has been demonstrated. Also, the ability of flexural toughness indexes to characterize the load-deflection curve has been shown. However, it is still relatively difficult to use a set of indexes in design. We need a simpler method of accounting for material brittleness in our design procedure.

Figure 5 illustrates the theoretical correlation between increasing $f_{f} / f_{\text {f }}$ ratios and decreasing material brittleness. Comparing Figures 6 and 7 shows correlation between increasing $f_{f} / f_{1}$ ratios and decreases in the initial descending slope of the softening 
curve for the materials used in this experimental programme. Experimental results presented by Petersson ${ }^{3}$ for various plain concrete qualities showed the $f_{f} / f_{t}$ ratio as an increasing function of the material

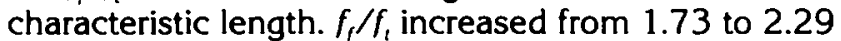
when $I_{c h}$ increased from 87 to $500 \mathrm{~mm}$. Neville ${ }^{18}$ presented test results for plain concrete showing the $f_{f} / f$, ratio decreasing from 1.78 to 1.57 when concrete compressive strength increases from 20 to $65 \mathrm{MPa}$ (2900 to $9425 \mathrm{psi}$ ). Thus, the $f_{f} / f_{1}$ ratio portrayed the greater brittleness of higher strength concrete. All these results suggest the possibility of using the simple parameter $f_{f} / f_{f}$ as a measure of material brittleness. Calculation of this parameter involves only two fast and simple laboratory tests, and it is thus ideally suited for design and quality control purposes.

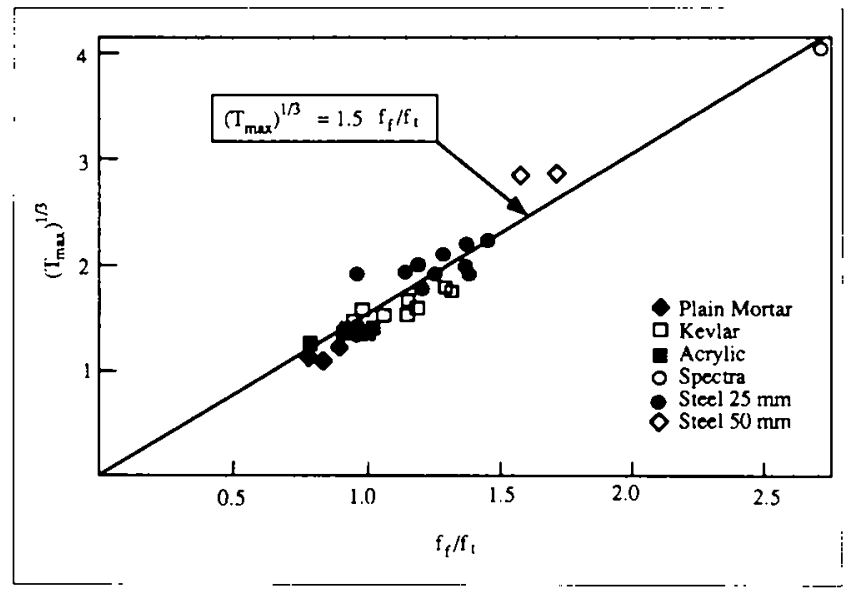

Fig 16 Semiempirical relationship between the flexural toughness index $T_{\text {max }}$ and the $\mathrm{f}_{\mathrm{f}} / \mathrm{f}_{\mathrm{t}}$ ratio

Comparison of Figures 7 and 13 shows that, in general, increases in the flexural toughness index $T_{\max }$ correspond to increases in the ratio $f_{f} / f_{\text {. }}$. Figure 16 illustrates reasonably good straight-line correlation between $\left(T_{\max }\right)^{1 / 3}$ and $f_{f} / f_{l}$ for all materials and beam sizes used in this testing programme. The equation for the straight line shown in Figure 16 is given as

$$
\left(T_{\max }\right)^{1 / 2}=1.50 f_{f} / f_{t}
$$

A high value of $f_{f} / f_{t}$ indicates a material with a relatively flat softening curve, which leads to relatively large inelastic deformation between initial matrix cracking and ultimate flexural strength. This also leads to a high $T_{\max }$ value. Also, the size dependence of the parameter $f_{f}$ accounts for the size dependence of $\left(T_{\text {max }}\right)^{1 / 3}$

The $T_{10}$ value is influenced both by inelastic energy absorption throughout the beam volume (including energy absorbed by multiple cracking) and also by the fracture energy absorbed across the fracture plane. The $f_{t} / f_{t}$ ratio can account for the distributed inelastic energy component. It may be expected that the fracture energy absorbed by the fibre pullout across the fracture zone is related to fibre bond strength and fibre length. A good bond strength gives high stress capability at relatively large crack opening. Another reasonable assumption is that there is a direct relationship between the flexural strength and the combined bond strengths

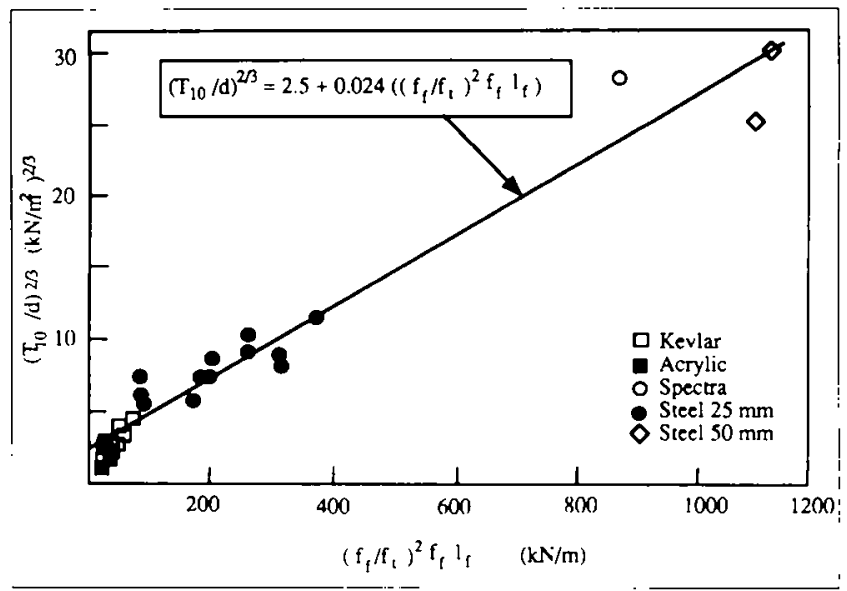

Fig 17 Semiemphirical relationship between the flexural toughness index $\mathrm{T}_{10}$ and a parameter involving the flexural and tensile strengths and the fibre length $[1 \mathrm{kN} / \mathrm{m}=5.7 \mathrm{lb} / \mathrm{in} . ; 1$ $\left.\left(k N / m^{2}\right)^{2 / 3}=0.276(p s i)^{2 / 3}\right]$

of all the fibres bridging the critical fracture zone. Thus, flexural strength can account for individual fibre bond strength together with the fibre volume fraction. This leads to the product of flexural strength and fibre length $f_{f} / l$ as a means of ranking materials according to the fracture energy (note that the units are similar). These arguments lead to the development of Figure 17, which shows reasonable straight line correlation between the parameter $\left(f_{f} / f_{t}\right)^{2} f_{f} / l_{f}$ and $\left(T_{10} d\right)^{2 / 3}$, for all materials and beam sizes. The formula for the straight line shown in Figure 17 is given as:

$$
\begin{gathered}
\left(T_{10} k d\right)^{2 / 3}=2.5+0.024\left[\left(f_{f} / f_{t}\right)^{2} f_{f} l_{f}\right] \\
3.62\left(T_{10} d d\right)^{2 / 3}=2.5+0.0042\left[\left(f_{f} f_{t}\right)^{2} f_{f} l_{f}\right]
\end{gathered}
$$

Units in Equation (4a) are given in $\mathrm{kN}$ and $\mathrm{m}$; units in Equation (4b) are given in pounds and inches. $T_{10} / d$ is indicative of energy absorbed per unit beam volume. The size dependence of $f_{f}^{3}$ accounts for the size dependence of $\left(T_{10} / d\right)^{3 / 3}$.

The results presented in Figures 16 and 17 suggest that we can gain an insight into the general shape of the flexural load-deflection curve by simply measuring the flexural and tensile strengths. It must be remembered that the measured splitting tensile strength depends on the cylinder size. It should not be unreasonable to suggest that the same standard cylinder size $152.5 \times 305 \mathrm{~mm}$ ( $6 \times 12 \mathrm{in}$.), as used for the compression test, be adopted as standard.

\section{Predicting ultimate shear strength}

Gustaffson ${ }^{4}$ showed the ratio $f_{v} / f_{l}$ as an increasing function of the parameter $l_{c h} / d$, using the fictitious crack model and finite element analysis. This suggests that the structural strength parameter $f_{v}$ depends on both the material strength $f_{t}$ and the material brittleness in the form of the parameter $I_{c h}$. An experimental programme reported by $\mathrm{Li}$ et al ${ }^{19}$ and Ward, ${ }^{8}$ used the same fibres as those in the testing programme reported here, to examine the influence of material fracture resistance on the ultimate shear 


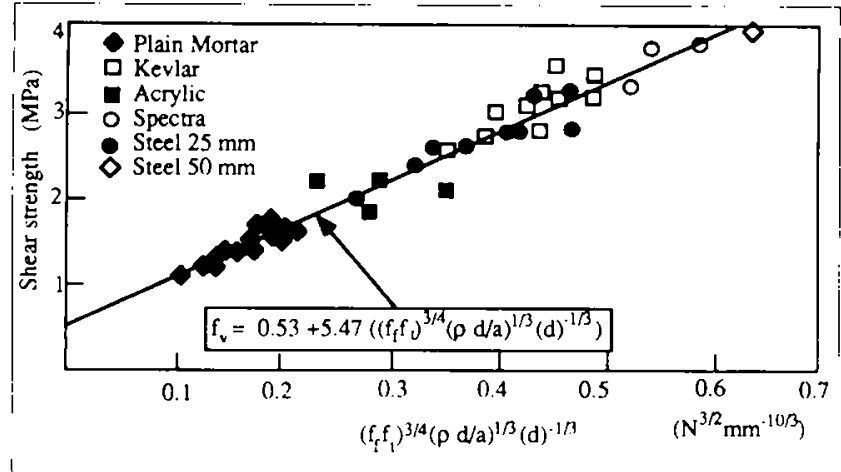

Fig 18 Semiempirical relationship between ultimate shear strength and the material and geometrical properties for ald $\geqslant 2.5(1 \mathrm{MPa}=145 \mathrm{psi}$; $I / N^{-3 / 2}=5133.6\left(b^{3 / 2}\right.$ in. $\left.^{-10 / 3}\right)$

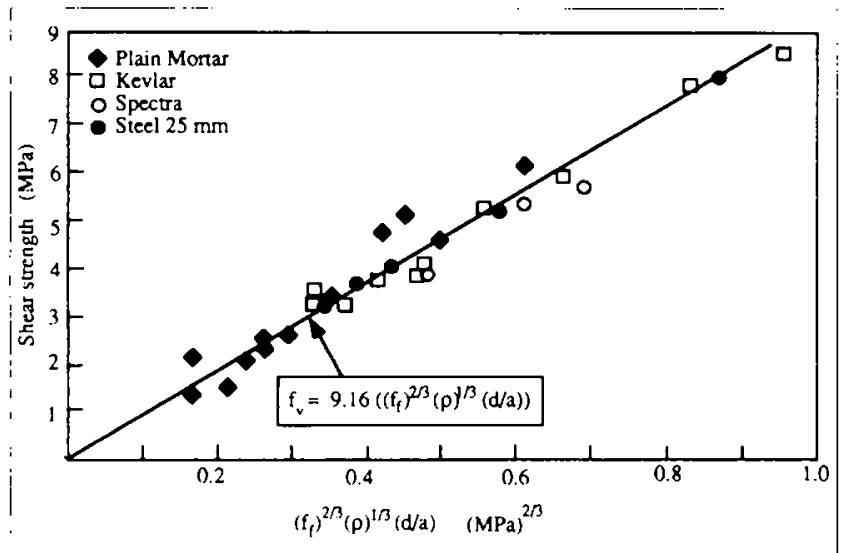

Fig 19 Semiempirical relationship between ultimate shear strength and the material and geometrical properties for ald $\leqslant 2.5(1 \mathrm{MPa}=145 \mathrm{psi} ; 1$ $\mathrm{MPa}^{2 / 3}=27.6 \mathrm{psi}^{2 / 3}$ )

strength of fibre reinforcing mortar beams with longitudinal reinforcing bar reinforcement only. In the experimental programme, the shear span/effective depth ratio $a / d$, the reinforcement ratio $\varrho$, and the effective beam depth $d$ were also varied to obtain the dependence of ultimate shear strength on these parameters as well. The results of the experimental programme are summarized in Figures 18 and 19. These results suggest that ultimate shear strength can be predicted by measuring only the flexural and tensile strengths and using a combination of these parameters to quantify the effect of fracture resistance on structural strength.

\section{Conclusions}

1. The trend of decreasing flexural strength with beam size increases is found to be similar for plain mortar reinforced with various steel and synthetic fibres. On average, the flexural strength decreases in proportion to $d^{-0.13}$, for similar beam geometry. The total energy absorbed per unit beam volume decreases as beam size increases, for similar beam geometry.

2. The ratio between the initial downward slope of the tension-softening curve and the slope of the stress-strain curve $l / l_{c h}^{\prime}$ is a good measure of material brittleness.
However, the tension-softening curve is, in general, too difficult and time-consuming to measure for practical implementation in routine design and quality control. Using a direct correlation between the effective material characteristic length $l_{c h}^{\prime}$ and the $f_{f} / f_{\text {, ratio, this ratio is }}$ suggested as a simple and practical measure of material brittleness, a low value signifying a brittle material.

3. By realizing the dependence of structural behaviour on material fracture resistance, and also the ability of the parameters $f_{f}$ and $f_{t}$ to characterize this dependence, it is possible to develop simple formulae that directly express this dependence. This procedure involves measuring only $f_{f}$ and $f_{t}$ in the laboratory and is, thus, ideally suited for design and quality control purposes. Successful implementation of this procedure for two structural applications, namely the load. deflection curve of unreinforced beams failing in flexure and the ultimate strength of longitudinally reinforcing beams failing in shear, has been demonstrated.

4. It must be remembered that the materials used in this programme, plain mortar and fibre reinforced mortar, are not materials that would be used in practical construction. However, they are similar to the mortar matrix which might be expected in medium to highstrength concrete and fibre concrete [over $40 \mathrm{MPa}$ $(5800 \mathrm{psi})]$. The main purpose of this testing programme was to establish a direction for further research on practical concrete mixes. It has established the important parameters that should be measured to verify the extension of these promising results in a practical application. Our primary future goal is to establish relationships which would be somewhat similar to those illustrated in Figures 16 to 19 , but which apply to practical concrete and fibre concrete mixes. This is a sizable undertaking and would require a large testing programme. However, the possible benefits for future concrete construction cannot be overstated.

\section{Acknowledgements}

The authors gratefully acknowledge the support of the National Science Foundation. They would also like to thank S. Backer, Y. Wang and E. Green for many helpful discussions during the course of this work. This paper appeared in the ACI Materials Journal, Nov-Dec 1990, and is reproduced by courtesy of the American Concrete Institute.

\section{References}

1 Hillerborg, A. Analysis of One Single Crack. Fracture Mechanics of Concrete, Elsevier Science Publishers, Amsterdam, 1983, pp. 223.250.

2 Hillerborg, A. Fracture Mechanics and the Concrete Codes Fracture Mechanics: Application to Concrete, SP.118, American Concrete Institute, Detroit, 1989, pp. 157.169.

3 Petersson, Per-Erik. Crack Growth and Development of Fracture Zones in Plain Concrete and Similar Materials, Report No. TVBM.1006, Division of Building Materials, Lund Institute of Technology, 1981, $174 \mathrm{pp}$.

4 Gustafseon, Per Johan. Fracture Mechanics Studies on NonYielding Materials like Concrete. Report No. TVBM-1007, Division of Building Materials, Lund Institute of Technology, 1985, 422 pp.

5 Henager, $\mathbf{C ~ H}$. Toughness Index of Fibre Concrete. Testing and Test Methods of Fibre Cerment Composites (RILEM Symposium 1978), Construction Press Ltd., Lancaster, pp. 79.86.

6 Johnston, C D. Definition and Measurement of Flexural Toughness Parameters for Fibre Reinforced Concrete. Cement. Concrete and Aggregates, V. 4, Mo. 2, Winter 1982, pp. 53.60. 
7 Wang, Youjlang and Backer, 8. Toughness Determination for Fibre Reinforced Concrete. Cement Composites and Lightweight Concrete, V11, No. 1, Feb. 1989, pp. 11.19.

8 Ward, $\mathbf{R}$ J. Structural Behaviour of Fibre Reinforced Mortar Related to Material Fracture Resistance. SM thesis, Department of Civil Engineering, Massachusetts Institute of Technology, Cambridge, June 1989.

9 Johnston, C D. Steel Fibre Reinforced and Plain Concrete: Factors Influencing Flexural Strength Measurement. ACl Joumal. Proceedings V. 79, No. 2, Mar-Apr. 1982, pp. 131-138.

10 Aklhama, 8, Suenaga, T and Nakagawa, H. Carbon Fibre Reinforced Concrete. Concrete International; Design $\mathcal{E}$ Construction, V.10, No. 1, Jan. 1988, pp. 40.47.

11 Torrent, $\mathbf{R} \mathbf{J}$, and Brooks, $\mathbf{J} \mathbf{J}$. Application of the Highly Stressed Volume Approach to Correlated Results from Different Tensile Tests of Concrete. Magazine of Concrete Research (London), V.37, No. 132, Sept. 1985, pp. 175.184.

12 L, V C and Ward, R J. Novel Testing Technique for Post.Peak Tensile Behaviour of Cementitious Materials. Proc Int Workshop on Fracture Toughness and Fracture Energy - Test Methods for Concrete and Rock (Sendai, 1988), A A Balkema Publishers, pp. $183-196$.

13 Wang, Y, L, V C and Backer, S. Tensile Properties of Synthetic
Fibre Reinforced Mortar. Int J Cement Composites and Lightweight concrete V.12, No.1, Feb. 1990, pp.29.42.

14 Hillerborg, $\boldsymbol{A}$. Determination and Significance of the Fracture Toughness of Steel Fibre Concrete. Steel Fibre Concrete (US-Sweden Joint Seminar, 1985). Swedish Cement and Concrete Institute, Stockholm/Elsevier Applied Science Publishers, London, 1986, pp. 257.271.

15 ACI Committee 544. State-of the-Art Report on Fibre Reinforced Concrete. (ACl 544.1R.73), American Concrete Institute, Detroit. 1973, 16 pp.

16 Hibbert, A P and Hannant, D J. Toughness of Fibre Cement Composites, Composites V13, No. 2, Apr. 1982, pp. 105.111.

17 Hillerborg, A. Analysis of Fracture by Means of the Fictitious Crack Model, Particularly for Fibre Reinforced Concrete. Int $J$ Cement Composites, V.2, No 4, Nov. 1980, pp. 177.184.

18 Neville, A M. Properties of Concrete, 3rd Edition. Pitman Publishers, Inc., Marshfield, 1981, p.304.

19 Li, V C, Ward, $\mathbf{R} \mathbf{J}$ and Hamza, A. Effect of Fibre Modified Fracture Properties on the Shear Resistance of Reinforced Mortar and Concrete Beams. RILEM International Workshop on Applications of Fracture Mechanics to Reinforced Concrete. Torino, 1990.

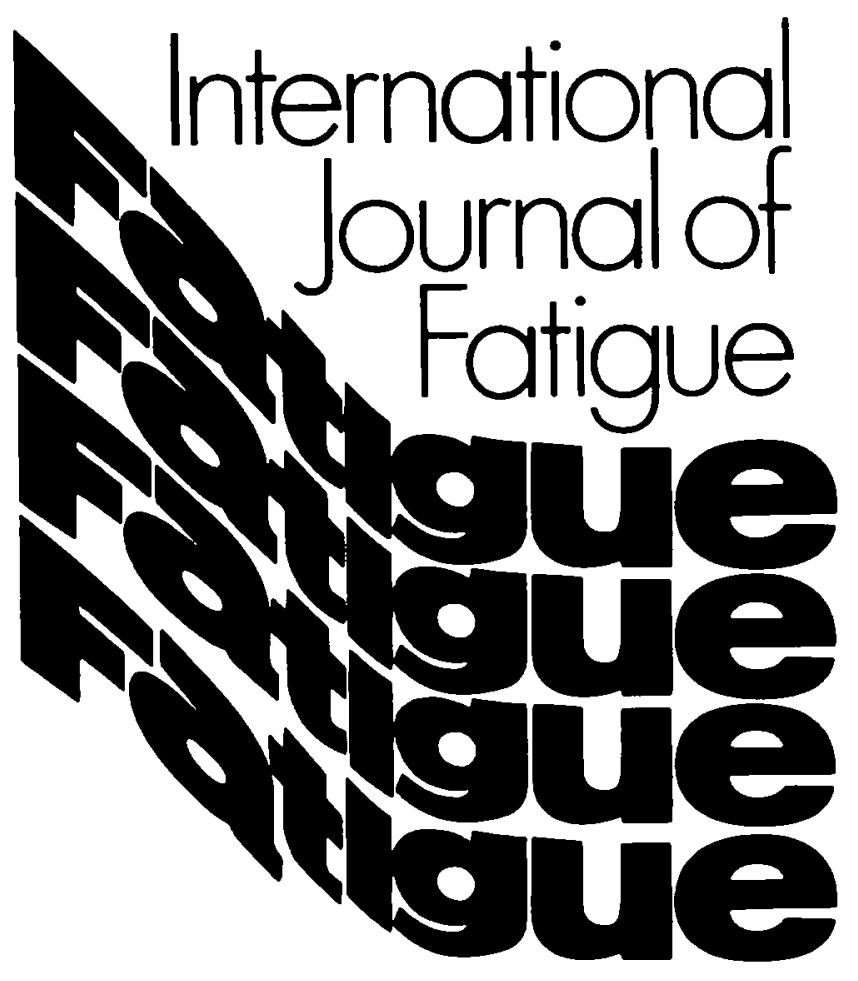

- Materials

-Structures

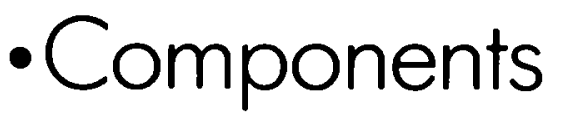

Articles, news and reviews on the fatigue behaviour of engineering materials. Includes Fatigue Abstracts.

Published bimonthly ISSN 01421123

For a FREE sample copy and further information contact Turpin Transactions, The Distribution Centre, Blackhorse Road, Letchworth, Herts SG6 $1 \mathrm{HN}$, UK

Tel: 0462672555 Telex: 825372

TURPIN G Fax: 0462480947

BUTTERWORTH 